\title{
The Effects of Feedbacks on Chinese Learners' English Learning Process: A Quantitative Analysis in Linguistics Correctness
}

\author{
Yuan Cheng ${ }^{1, \dagger}$ Shunyu $\mathrm{Yao}^{2, *}, \dagger$ Yiyin Zhang ${ }^{3, \dagger}$ \\ ${ }^{1}$ Zhujiang College Of South China Agricultural University, Guangzhou, Guangdong, China \\ ${ }^{2}$ The Master' s School, West Simsbury, CT, United States \\ ${ }^{3}$ Beijinghuijia private school, Beijing, China \\ *Corresponding author Email: shunyu.yao@gordon.edu \\ Those authors contributed equally.
}

\begin{abstract}
Since the population of educated people gradually increases, studying a foreign language has become a common choice for a major or interest. Based on the general understanding of Second Language Acquisition, learners from varied regions tend to obtain different focuses on language learning. This paper focuses on linguistic correctness in the Chinese environment affecting the English learning process to specify the research topic. This paper uses qualitative analysis to differentiate and summarize the concept of linguistic correctness in China and its influence on English learning, implying that research can be a helpful resource for linguistics and education studies. In Asia, many countries have incorporated English into their teaching systems, and English has become one of the compulsory courses in education. Since China has a large population, English learners make up a considerable percentage of the total population. Thus, in this essay, the focus is to go deeper into their perceptions of the linguistic correctness of English, taking English learners in China as the main object of our study.
\end{abstract}

Keywords: Second Language Acquisition, Foreign Language, Linguistic Correctness, China.

\section{INTRODUCTION}

English spread to many countries worldwide as an international language. In Asia, many countries incorporate English into their teaching systems. Thus, English has become one of the compulsory courses in education. As China is a country with a massive population, the widespread of English make up a large percentage of the total population of foreign language learners. The focus is on English learners in China as the main object of our study to go deeper into their perceptions of the linguistic correctness of English.

In this paper, the analysis will concentrate on the unique perspectives of Chinese learners and their cultural connotations, including central values that influence Chinese learners in L2 acquisition, language learning in both qualitative data and previous authoritative contents.

This paper focuses on Chinese learners' crucial characteristics and the influences generated from the Chi- nese cultural backgrounds. The collectivist style is the most significant trait in Chinese culture, which is combined with the idea of harmony and low-self concept, integrating to part of people's value through enculturation. Since language is a massive part of the culture, cultural dimensions provide the basis for learning. Thus, the orientations of Chinese learner acquiring L2 is revealing by using English as a typical example that can demonstrate the effect of cultural connotations on L2 acquisition. Under all language branches, linguistic correctness is the central theme that is often influenced and varied by cultural perceptions. Consequently, it becomes the subject for investigation in the effects of feedback on the English learning process of Chinese learners.

The data for supporting this research paper would mainly focus on The Authority of Language, by James Milroy and Lesley Milroy, plus other documents with a similar topic.[4] Additionally, we will use our daily life experiences as primary resources and analyze these resources using the quantitative method by acknowledg- 
ing linguistic correctness and SLA development characteristics.

\section{EFFECTS OF CONSERVATIVE CUL- TURAL ATTITUDES}

The unique characteristics of Chinese cultural influences shape the conservative learners from that particular region. The overdue recognition of order, conservative views, disciplinary society, and low self-concept in the culture lead to considerable differences in English skills. Over-emphasizing traditional grammar affects Chinese learners' behaviors during the English learning process. The high standard of requiring lexical resources in Chinese societies has also applied to the SLA development, focusing on remembering grammatical rules and meanings of words. In contrast, the lack of focus on external communicative competence results in the most common mistakes in East Asian learners' SLA process and illustrates the influence of East Asian culture.

\subsection{Collectivism Chinese culture}

Collectivism refers to political or economic theory advocating collective control, especially over production and distribution. This particular type of group dynamic generates strict social norms that center on the idea of group harmony. China is a classic example utilizing collective strategies to manage the whole society. Under the influence of collectivism, exacting attitudes and beliefs of orders make Chinese learners very conservative in linguistic correctness in terms of English acquisition as L2. In other words, their cultural beliefs decide their language usage and then influence their language acquisition performance.

A crucial perspective showing a cautious way for Chinese learners under the influence of collective cultural norms is language acquisition. Chinese learners are conscientious at pronunciation, but their speaking habits are stiff in grammar and word choice. Many crossculture study has provided analysis of Chinese culture in terms of L2 acquisition. One of the cross-cultural studies that Heath and Shirley Brice1 focus on is the socialization of Language, which is the concept deeply coded with cultural influence.[1] In the study, researchers gathering participants in childhood between 6 and 10 years old-all participants are from different cultural backgrounds, including European and Asian cultures. One of the cultural groups is Chinese culture.

The conclusion is drawn from a preliminary comparison of children's responses to language usage in different social situations. The findings suggest that academic success depends not only on the specific language children learn but on using languages. Discoveries of Heath and Shirley about the usage of Language have supported the claims about the bridge between cultural influence and the idea of language acquisition.
Conservative and reserved attitudes are influential core factors of Chinese learners in L2 acquisition for English. The paper will highlight the unique point of Chinese culture and students who have Chinese background as a particular group among all the cultures in the world. The Chinese education system is traditional and out of the ordinary under the influences of cultural connotations. Chinese learners are under a serious school climate. As a result, their way of thinking is always learned from textbooks, which is less flexible and rarely used for daily expression for L1 speakers. At the same time, the school system can give students lowself-concept under the influence of a collectivist society, which makes students follow the rules even more orderly. Those ideas from this paper will be displayed great extents of culture-related property for language acquisition in English.

A study from Educational Research Journal done by Sui-chu Ho consolidates cultural influence on Chinese learners.[2] Because of the typicalness, this study also uses English as an example to investigate L2 acquisition. By using the PISA database, following the rules and strict study climates, two of the most important Chinese learners' claims will be summarized in this paper. They correspond to the passivity in Chinese learners caused by cultural ideologies as the product of the educational system, which is also supportive of the claims of the hypothesis above.

\subsection{Formation of strict learning style}

Although argumentative points existing for Chinese culture, the common traits of Chinese thinking style in language acquisition are often unified: strict learning styles in a conservative manner influence language usage, including pronunciation, word choice, and lexicons. Authority in Language talks about how cultural influences result in language learning style in many aspects. From my angle, the point of Chinese culture is also at their strict way of thinking. Examples in the book mentioned culture many times, and their language usage is described excitingly since their unique cultural backgrounds and social norms.

The strict learning style of Chinese people leads to their cultural adaptation. As a multicultural language in multiple countries, English is not predicated on forcing Asian countries to adapt to the culture of Englishspeaking countries. [10] In contrast, L2 acquisition of English is a process of integration and adaptation based on mutual respect. The Culture on Second Language Communicative Competence Acquisition and English as Multicultural Language in Asian and Intercultural Literacy argue that a plausible way of managing the multiculturalism of Asian English is not standardization but intercultural literacy.[3] 
Under this background, two major characteristics of contemporary English are the global spreading and the development of distinct varieties. Structurally, as the speed of English progresses, it is inevitable that English also reflects the diversities of different cultures. [9] Importantly, non-native speakers are taking advantage of this. They are exploring new dimensions of English phonological usage in vocabulary, syntax, semantics, and pragmatics. In this paper, I will use an experience to express the differences between Chinese and native English speakers when expressing themselves in English.

Asian learners seem to prefer euphemisms, which they consider as a sign of politeness. A phenomenon that can be attributed to the ideology of Asian languages, which to some extent reflects the Asian view of life as being subtle and introverted and the expected result of social, family, and school education. To sum up, the concept of English as a multicultural language is based on the fact that English will continue to exist as an indispensable language in domestic or international communication in Asia and the rest of the world.

\section{LINGUISTIC CORRECTNESS OF CHI- NESE LEARNER}

Linguistic correctness is the synonym of linguistic prescriptivism of speaking habits or only the grammatical rules listed in a lexicon. The cultural influence on linguistic correctness would also cause issues in English acquisition, especially the emergence of localized abbreviations. The interlanguage stage still requires transferring a native language to the second language, which always contains words and metaphrase sentences - as one manifestation of localized abbreviations. The common mistakes such as applying the logic and structure of learners' native language to English reflect the variety in linguistic correctness.

\subsection{Effects of Learning habits in Second Lan- guage Acquisition}

Linguistic correctness is the idea of correctness in Language that is sometimes referred to as linguistic prescriptivism, usually in terms of speech. The term prescriptivism refers to the ideology and practices in which the correct and incorrect uses of a language or specific linguistic items are laid down by explicit rules externally imposed on the users of that Language. This ideology and its practices are now usually ascribed to no linguists or nonacademic linguists. In contrast, following Saussure and tenets4, modern academic linguists restrict themselves to the study and description of the structure of Language and its natural use.

Linguistic correctness is the central point supporting the idea of cultural influence on Chinese learners in L2 acquisition. The variation of linguistic correctness con- nects with cultural contexts shaped by the strict collective Chinese cultural atmosphere. The Authority of Language, by James Milroy and Lesley Milroy, explores the perennially topical and controversial notion of correct and incorrect Language, the ideological Language's corresponding part.[4] Ideological Language reflects the views, beliefs, and attitudes of a person or group in terms of their worldview, outlook on life, and values. Ideological Language is a way of communication. Generally, it reflects the characteristics of an individual or a group of people and can be referred to as "linguistic ideology" also.

Language is the product of culture and is the symbol of culture. Therefore, the most striking feature of Chinese learners' language learning culture is following the rules and being disciplined. Both teachers and students follow this pattern in teaching and receiving learning, which lead to the Chinese forming an idea of linguistic correctness in a conservative and disciplined manner. Specifically, cultural contents affect cognitive patterns of Chinese learners in the way of L2 acquisition. Cognitive pattern refers to the mode in which learners acquire and process information, which can be affected by the learner's mother tongue and culture. This way can explain the linguistic prescriptivism of linguistic correctness in ideologies and beliefs, reflecting in Chinese learners' cognitive patterns.

The Chinese language rules and culture influence the English learning process of Chinese learners, which can result in positive or negative transfers in listening, speaking, reading, and writing in English. A Study of The Influence of Chinese Language extracts effects learning from aspects of listening, speaking, reading, and their language and culture influence writing of Chinese students in English learning.[5] As for speaking competence, and the author only focuses on discourse and cultural pragmatics. Moreover, he mentions the influence of the Chinese Language and culture on acquiring second listening competence. Listening comprehension is the process of listening decoding. In this process of decoding, language transfer also occurs.

Chinese reading habits, including thinking styles and cognitive strategies, are all outcomes of cultural influence. Thus, Chinese Language and culture are exploitable resources in acquiring second language communicative competence for linguistic correctness. The influences are both positive and negative. There are several aspects of positive transfer in listening, including the transfer of language and culture and pragmatic inference. Furthermore, the transfer of cognitive, especially to the cognitive pattern of native Language, may rise to the positive transfer and negative transfer in listening comprehension. However, the transfer of discourse occurs at the same time. As a result, Chinese learners are also influenced by their native culture to apply their native language's pragmatic rules in acquiring L2. 


\subsection{Systematic Implications behind Chinese language acquisition}

The common characteristics of Chinese cultural influences the conservative learners from the particular region. Over-emphasizing traditional grammar as the center of linguistic correctness affects East-Asian learners' behaviors during the English learning process. "Language is not only the product of culture but also is the symbol of culture," from The development of Language, by Jean Berko Gleason.[6] The culture must have an essential connection with the use of Language and the development of SLA.

The ideological situation among most Asian countries is relatively conservative. The overdue recognition of order, conservative views, disciplinary society, and low self-concept in the culture lead to considerable differences in English skills. The traditional Chinese society is disciplinary and orderly, which shapes the relatively conservative characteristics of Chinese citizens. Thus, Chinese learners are more likely to follow the rules in grammar due to their disciplined manner.

In addition, to conclude concepts from literature devices, other research projects also reveal many particular aspects of Chinese culture's influence on the English development process.[7] Communicative competence often represents the cultural influence on transferring from a native language to English; the common mistakes such as applying the logic and structure of learners' native Language to English formation reflect the variety in linguistic correctness. The high standard of requiring lexical resources in Chinese societies has also applied to the SLA development, focusing on remembering grammatical rules and meanings of words. For example, Chinese students tend to receive higher scores in examining English reading and grammar skills. These two parts represent grammatical rules and recitation rather than the flexibility and understanding of a language. As a result, Chinese learners may have an advantage in writing language as their focus, which is not centered on external communicative competence but on the traditional grammar and lexical resources.

In terms of communicative competence, the development in SLA often includes four sections: listening competence, speaking competence, reading competence, and writing competence. Since the former two parts of competence all include pragmatics and discourse, which reflects the cultural effects most obviously, a gap between East Asia and Anglophone society in understanding linguistic correctness is widened. The range of linguistic correctness is not only through written languages and the accurate grammatical usage of utterances. The lack of focus on external communicative competence results in the most common mistakes in Chinese learners' SLA process and illustrates the influence of Chinese culture.
The education system is another influential segment under the particular cultural atmosphere in East Asia, also mirroring a different focus in language learning. Mainly, the students in Chinese countries acquire English ability through schools and textbooks. The way of analyzing the importance of each part in English communicative competence is uniquely corresponding to the linguistic correctness in Chinese cultural background: often values abundant lexical resources, syntax, and euphemistic expressions; these concepts applies to the way of teachings, eventually leading students to put more efforts in reciting words and grammatical rules. The cultural influence on linguistic correctness, therefore, also causes issues in English acquisition, especially the emergence of localized abbreviations.

The interlanguage stage still requires transferring a native language to the second language, which always contains the translation of words and metaphrase sentences - as one manifestation of localized abbreviations. The other localized abbreviation resulting from the textbook usage is that some particular English phrases only exist under the Chinese education system, which the native speakers never use. For example, phrases such as "so so" would only occur in Chinese English textbooks, and no English native speaker would use this phrase in pragmatic expressions.

As the identities of all the members in this research project are Asians, we consider using real-life experiences as primary data to support the research paper by interviewing the students and teachers around our lives as potential resources. The mismatch of understandings in linguistic correctness under different cultures would leave the gap in the interlanguage stage to maintain. According to Ray Lagan, the former headmaster of The Master's School, comprehension and vocabulary are the only two requirements to achieve the correct usage of English under the Anglo culture environment. Although the definition of comprehension acquires the ability to use vocabulary, its importance can be an independent aspect. In contrast, concepts of language correctness in East Asia require the ability to comprehend and fluency, logic, pronunciation, and euphemistic expression in speaking competence. Consequently, applying Chinese linguistic correctness to the SLA process enables the learners to put more effort on written language.

\section{CONCLUSION}

The purpose of this paper is to examine Chinese learners' perceptions of English language correctness under the influence of Chinese language and culture and to dissect their impact on the localization of English education and communication development in China by explaining the concept of linguistic correctness and the main features of linguistic correctness developed in the general English acquisitive process. 
The analytical concepts provided by previous sections state the vast influence of Chinese culture on the English learning process. The unequal cultural aspects of language correctness in a specific region establish the connection between the native language's inherent concepts and the SLA process often negatively. Chinese cultural background influences linguistic correctness in traditions, social ideology, native languages, and native education. The combined cultural influences lead to numerous obstacles that Chinese learners would encounter through their SLA development.

As the demand for each citizen in society gradually increases, more students nowadays choose to study several foreign languages. Since the culture influences a learner in all-round, our research topic provides the methods and examples of how to find out the negative effects from a cultural perspective and engage in solving them, not only for Chinese learners. The SLA process includes acquiring various information under linguistic prescriptivism and demanding to accept cultural particularity. The regulation in linguistic correctness does not aim to help learners avoid errors during academic study but to improve the comprehension of a new language and concept.

The implications in this paper are that proper linguistic correctness is beneficial to ESL teaching, and reshaping the perspective of correctness can be more helpful in SLA.[8] Because it helps to recognize cultural gaps, more excellent knowledge of the cultural effecting on linguistic correctness can enhance English education. Understanding linguistic correctness under the Chinese culture and language also boosts the development of English as an international language in Asia.

\section{REFERENCES}

[1] Shirley Brice Heath 2011. "Language Socialization in Art and Science". In The Handbook of Language Socialization. A Duranti, E. Ochs, \& B. Schieffelin, eds. London: Blackwell Publishers. Pp. 425442

[2] Sui-chu, Ho. "Characteristics of East Asian Learners: What We Learned From PISA." Hong Kong Educational Research Association, 2009

[3] Honna, Nobuyuki. English as a Multicultural Language in Asia and Intercultural Literacy, 2005, web.uri.edu/iaics/files/06-Nobuyuki-Honna.pdf.

[4] Milroy, J., \& Milroy, L. (2012). Authority in Language: Investigating Standard English (1st ed.). Routledge. https://doi.org/10.4324/9780203124666

[5] Li, Dongmei, and Xiaoxiao Mao. A Study of the Influence of Chinese Language and Culture on Second Language Communicative Competence
Acquisition. 2015, www.atlantispress.com/article/23991.pdf.

[6] Cameron-Faulkner, Thea \& Matthews, Danielle \& Serratrice, Ludovica. (2010). Jean Berko Gleason (ed.), The development of language, 6th edn. Boston, MA: Pearson, 2005. Pp. 516. ISBN 0205394140.Robert E. Owens, Language development: An introduction, 7th edn. Boston, MA: Pearson, 2008. Pp. 509. ISBN 0023901810.William O'Grady, How children learn language. Cambridge: Cambridge University Press, 2005. Pp. 248. ISBN 0521531926 (paperback).. Journal of Child Language - J CHILD LANG. 37. 10.1017/S0305000909009453.

[7] Chan, YeeHim. "PDF." The Journal of Asia TEFL, 2018,

file://Users/shunfish/Desktop/de62d7b3d4aca5048 0dde063a551bd42.pdf

[8] Ansari, M. S. (2015). Speaking Anxiety in ESL/ EFL Classrooms: A Holistic Approach and practical study. International Journal of Education Investigation, 2(4), 38-46.

[9] Muriel, Saville. introducing Second language Acquisition. New York: Cambridge, 2016. Print.

[10] Chomsky, Noam. Reflections on Language. U.S: Ashgate Publishing Limited, 1972. Print. 